\title{
Pilot trials in physical activity journals: a review of reporting and editorial policy
}

\author{
Elsie Horne ${ }^{1 *}$ (D), Gillian A. Lancaster ${ }^{2}$, Rhys Matson ${ }^{1}$, Ashley Cooper ${ }^{1,3}$, Andy Ness $^{1}$ and Sam Leary ${ }^{1}$
}

\begin{abstract}
Background: Since the early 2000s, a number of publications in the medical literature have highlighted inadequacies in the design, conduct and reporting of pilot trials. This work led to two notable publications in 2016: a conceptual framework for defining feasibility studies and an extension to the CONSORT 2010 statement to include pilot trials. It was hoped that these publications would educate researchers, leading to better use of pilot trials and thus more rigorously planned and informed randomised controlled trials. The aim of the present work is to evaluate the impact of these publications in the field of physical activity by reviewing the literature pre- and post-2016. This first article presents the pre-2016 review of the reporting and the current editorial policy applied to pilot trials published in physical activity journals.
\end{abstract}

Methods: Fourteen physical activity journals were screened for pilot and feasibility studies published between 2012 and 2015. The CONSORT 2010 extension to pilot and feasibility studies was used as a framework to assess the reporting quality of the studies. Editors of the eligible physical activity journals were canvassed regarding their editorial policy for pilot and feasibility studies.

Results: Thirty-one articles across five journals met the eligibility criteria. These articles fell into three distinct categories: trials that were carried out in preparation for a future definitive trial (23\%), trials that evaluated the feasibility of a novel intervention but did not explicitly address a future definitive trial (23\%) and trials that did not have any clear objectives to address feasibility (55\%). Editors from all five journals stated that they generally do not accept pilot trials, and none gave reference to the CONSORT 2010 extension as a guideline for submissions.

Conclusion: The result that over half of the studies did not have feasibility objectives is in line with previous research findings, demonstrating that these findings are not being disseminated effectively to researchers in the field of physical activity. The low standard of reporting across most reviewed articles and the neglect of the extended CONSORT 2010 statement by the journal editors highlight the need to actively disseminate these guidelines to ensure their impact.

Keywords: Literature review, Pilot trial, Feasibility study, Physical activity, Editorial policy

\section{Background}

Pilot trials play a crucial role in the design of randomised controlled trials (RCT). They provide an opportunity to identify and address feasibility issues prior to the main RCT, thus avoiding the wasted resources and unnecessary participant burden that can incur from poorly designed RCTs. However, there is some confusion

\footnotetext{
* Correspondence: elsie.horne@ed.ac.uk

${ }^{1}$ National Institute for Health Research Bristol Biomedical Research Centre, University Hospitals Bristol NHS Foundation Trust and University of Bristol, 3rd Floor, Education \& Research Centre, Upper Maudlin Street, Bristol BS2 $8 \mathrm{AE}, \mathrm{UK}$

Full list of author information is available at the end of the article
}

in the research community over the definition, purpose, conduct and reporting of pilot studies. A number of publications describe the tendency for small underpowered studies which focus on testing efficacy or effectiveness to be inappropriately described by authors as pilot or feasibility studies [1-4].

In response to these findings, 2016 saw the release of two notable publications that aimed to address the inadequacies and misunderstandings surrounding pilot and feasibility work. The first, published in March 2016, addressed the inconsistencies in the use of the terms pilot and feasibility across medical literature [5]. This

(c) The Author(s). 2018 Open Access This article is distributed under the terms of the Creative Commons Attribution 4.0 International License (http://creativecommons.org/licenses/by/4.0/), which permits unrestricted use, distribution, and 
publication presented a conceptual framework for defining feasibility and pilot studies in preparation for RCTs. The authors concluded that feasibility is an overarching term that asks whether something will work. A feasibility study asks whether something can be done, should we proceed with it and if so how. A pilot study is a study in which a part or a whole of a future study is conducted on a smaller scale to see whether it will work. Therefore, all pilot studies are feasibility studies, but not all feasibility studies are pilot studies. To clarify, a study in which participants fill in a questionnaire to assess the types of outcomes that they think are important is given by Eldridge et al. as an example of a feasibility study which is not a pilot study [5].

The second paper, published in September 2016, presented a Consolidated Standards of Reporting (CONSORT) 2010 statement extension to include randomised pilot and feasibility trials carried out in advance of a future definitive trial [6]. For brevity, we will refer to this publication as the CONSORT 2010 extension. Eldridge et al. use the term pilot trial to refer to "any randomised study in which a future definitive RCT, or a part of it, is conducted on a smaller scale" [6]. We will use the term pilot trial to refer to any article that fits the inclusion criteria outlined in our methods section. In theory, this should be consistent with the terminology used by Eldridge et al.

While these two publications have the potential to mark a turning point in the conduct, reporting and publication of feasibility work, it is important to evaluate the impact. The challenges and uncertainties faced when carrying out a trial can vary depending on the area of research, making it informative to evaluate the impact of these guidelines in specific fields. Physical activity is a growing field of research due to its associations with some of the most prevalent morbidities in western society, such as type 2 diabetes, cardiovascular disease and certain cancers $[7,8]$. Some examples of uncertainties and challenges faced in this field include recruiting hard-to-reach individuals [9], measuring physical activity in a free-living setting (physical activity carried out in a participant's own environment at their own pace) [10] and initiating and maintaining behaviour change, particularly in older people [11]. It is an essential pre-requisite to the development of effective physical activity interventions that the uncertainties surrounding definitive trials are appropriately addressed in advance by well-conducted pilot trials. Furthermore, pilot trials should be reported in a transparent manner to inform other researchers in the field.

The overall aim of this work is to evaluate the impact of the CONSORT 2010 extension in the field of physical activity. This will be done by reviewing the reporting of pilot trials in physical activity journals before and after the 2016 publication of the CONSORT 2010 extension. This first article presents a review of articles published in 2012-15. Our intention is to carry out a follow-up review of articles published in 2018-21 to evaluate the impact. The objectives of both will be to review the reporting and methodological components of external randomised pilot trials across a selection of physical activity journals and to review the editorial policy regarding the publication of pilot and feasibility trials across these journals.

\section{Methods}

\section{Identification of articles}

Our initial review was carried out across 14 journals (Table 1) concerned with physical activity, exercise and sport. These 14 journals were intentionally generic and not specific to conditions or populations, for example we included the Journal of Physical Activity and Health but excluded the Journal of Physical Activity and Ageing. MEDLINE was searched for articles with either randomised or randomized, and either pilot or feas" in the title or abstract, restricting the search to the years 2012-15 and the 14 generic physical activity journals. Articles were eligible if they fulfilled either of the following two criteria: they identified as either a pilot or feasibility study in the title OR they explicitly identified as a pilot or feasibility study in the abstract or introduction (e.g. "This pilot/feasibility study..."). Articles were excluded if they were either not randomised or they reported an internal pilot trial. Articles from journals with five or more eligible articles were included in the literature review, and these journals were included in the review of editorial policy.

\begin{tabular}{ll} 
Table 1 Physical activity journals \\
\hline 1 & Medicine \& Science in Sports \& Exercise \\
2 & British Journal of Sports Medicine \\
3 & Sports Medicine \\
4 & American Journal of Sports Medicine \\
5 & International Journal of Behavioral Nutrition and Physical Activity \\
6 & Journal of Science and Medicine in Sport \\
7 & Journal of Physical Activity and Health \\
8 & Scandinavian Journal of Medicine \& Science in Sports \\
9 & Journal of Sports Medicine \\
10 & Journal of Sports Medicine and Physical Fitness \\
11 & Journal of Sports Science and Medicine \\
12 & Journal of Sports Sciences \\
13 & Clinical Journal of Sport Medicine \\
14 & European Journal of Sport Science \\
\hline
\end{tabular}




\section{Data extraction}

A data extraction form was developed using the CONSORT 2010 extension as a guide [6]. The development of the form was an iterative process that involved two reviewers piloting it on three articles and updating the form according to disagreements in responses. Data were extracted from each article by two independent reviewers. We did not extract data corresponding to every item on the CONSORT 2010 extension, but instead focused on the items that address features which have been identified by previous research as the main shortcomings of pilot trials $[2,4,5]$. Briefly, these features are the justification of the pilot trial as an assessment of the feasibility of a future definitive trial and the inappropriate use of hypothesis testing in pilot trials. The included CONSORT 2010 extension items are detailed in Table 2.

\section{Title and abstract}

Inconsistencies in the use of the terms pilot and feasibility have been highlighted by previous publications [2, 12]. This issue was addressed by Eldridge et al. in their development of a conceptual framework for defining feasibility trials in preparation for RCTs, published in 2016 [5]. This motivated the extraction of data related to item 1a. Contrasting the use of the terms pilot and feasibility before and after this publication provides the opportunity to evaluate whether it affected terminology in this field.

\section{Introduction}

To assess adherence to item $2 a$, we recorded whether the article gave rationale for the future definitive trial and rationale for carrying out a pilot trial. Corresponding to item $2 b$, we recorded whether the article gave clear objectives to assess the feasibility of a future definitive trial.

\section{Methods}

To investigate the design of the pilot trials in our review, we extracted data corresponding to items $3 \mathrm{a}$ and 5 . To address item $3 a$, we categorised the articles into the following groups, based on their design: parallel, crossover, cluster, waitlist control and other. The inclusion of a control group is not mandatory in pilot trials; a control group should only be included if it is necessary for addressing uncertainties regarding the future definitive $\mathrm{RCT}$. We recorded whether the trial included a control group, corresponding to item 5 .

Pilot trial objectives should address the feasibility of a future definitive trial, making items $6 a$ and $6 c$ key to the appropriate reporting of a pilot trial. The outcomes to address these objectives should be completely defined and pre-specified, as per item $6 a$. Each outcome should

Table 2 CONSORT 2010 extension [6] items corresponding to extracted data

\begin{tabular}{ll}
\hline Item number & Checklist item \\
\hline Title and abstract & $\begin{array}{l}\text { Identification as a pilot or } \\
\text { feasibility randomised trial in the title }\end{array}$
\end{tabular}

Introduction

$2 a$

$2 b$

Methods

$3 a$

5

$6 a$

$7 a$

$12 \mathrm{a}$

Discussion

20

21

$22 a$
Scientific background and explanation of rationale for future definitive trial and reasons for randomised pilot trial

Specific objectives or research questions for pilot trial

Description of pilot trial design (such as parallel, factorial) including allocation ratio

The interventions for each group with sufficient details to allow replication, including how and when they were actually administered

Completely defined pre-specified assessments or measurements to address each pilot trial objective specified in 2b, including how and when they were assessed

If applicable, pre-specified criteria used to judge whether, or how, to proceed with future definitive trial

Rationale for numbers in trial

Methods used to address each pilot trial objective whether qualitative or quantitative

Pilot trial limitations, addressing sources of potential bias and remaining uncertainty about feasibility

Generalisability (applicability) of pilot trial methods and findings to future definitive trial and other studies

Implications for progression from pilot trial to future definitive trial, including any proposed amendments

correspond to a specific aspect of feasibility being addressed by the pilot trial.

Thabane et al. [1] proposed four aspects to broadly classify the different rationale for performing a pilot trial; full details on these aspects can be found in their paper. Briefly, the four aspects are process (e.g. recruitment and retention rates), resources (e.g. cost, time, equipment), management (e.g. data entry and storage) and scientific (e.g. dose). We used this classification, including two further categories, to explain the aspects of feasibility addressed by the pilot trials. The two further categories 
added were sample size (pilot trial used to inform the sample size calculation for future definitive trial) and feedback (pilot trial used to collect qualitative or quantitative feedback from participants and staff, e.g. to explore the acceptability of the intervention or suggestions for improvements).

For an article to qualify as having addressed any of these aspects of feasibility, the aspect had to be addressed explicitly as an objective in the introduction or as an outcome in the methods section. If applicable, pre-specified criteria should be applied to these outcomes in order to inform the progression to a future definitive trial, corresponding to item $6 c$.

While a formal sample size calculation is not a requirement in pilot trials, the article should give a rationale for the number of participants in the trial, corresponding to item $7 a$. We extracted two pieces of information regarding sample size from each article. The first was whether the study gave rationale for the number of participants in the study, based on the numbers required to assess feasibility of the future definitive trial. The second was whether a sample size calculation had been carried out, based on hypothesis testing of the primary outcome intended for the future definitive trial. The latter refers to the type of sample size calculation that should be carried out in a definitive RCT, whose primary objective is to assess the effectiveness of an intervention.

A previous literature review identified that pilot trials put inappropriate emphasis on hypothesis testing [2]. The CONSORT 2010 extension explains in reference to item $12 a$ that "any estimates of effect using participant outcomes as they are likely to be measured in the future definitive RCT would be reported as estimates with 95\% confidence intervals without p-values" [6]. Corresponding to this item, we recorded whether hypothesis-testing of effectiveness was carried out.

\section{Discussion}

Discussions of pilot trials have been shown to be particularly poorly reported [4]. Shanyinde et al. highlight that discussions of pilot trials often focus on efficacy, rather than feasibility issues or the planning of future trials [4]. In line with this, it is important to distinguish items 20 and 21 in the CONSORT 2010 [6] extension to pilot trials to items 20 and 21 in the CONSORT 2010 statement for definitive RCTs [13].

The "limitations and sources of potential bias" part of item 20 (CONSORT 2010 extension) should be considered in reference to the progression to a future definitive $\mathrm{RCT}$, and how the design could be altered to overcome them. Similarly, the generalisability referred to in item 21 (CONSORT 2010 extension) should be considered in the context of generalisability of findings and methods to a future definitive RCT, rather than generalisability of findings to a clinical setting, as is the case when discussing the findings of a definitive RCT. The information extracted corresponding to these items is presented under the following headings: sources of potential bias, remaining uncertainty about feasibility and generalisability to future definitive trial.

As pilot trials should be carried out primarily to assess feasibility of a future definitive RCT, the implications for a future definitive RCT should be made clear in the discussion of the pilot trial, as per item $22 a$. We extracted information regarding the implications for a future definitive RCT, the planned progression to a future definitive RCT and the realised progression to a future definitive RCT. Planned progression was categorised as future definitive RCT planned without any changes, planned with changes from the pilot trial, not planned because of major problems with feasibility or unclear. The information for realised progression to future definitive trial was obtained by an online search as a first step, and where this did not produce results, we contacted the first author of each article by email to request the information. Realised progression was categorised as definitive RCT completed, definitive RCT registered, definitive RCT not registered or no information (if both our online search was unsuccessful and we did not receive a response to the email enquiry).

\section{Editorial policy}

Editors of the physical activity journals with five or more eligible articles received an email enquiry regarding their editorial policy for pilot trials. All editors were sent an initial email and a follow-up email 1 month later if they did not respond. Their responses, along with the information provided on the journal website, are included in this review.

\section{Results}

Figure 1 illustrates the flow of articles into the review and names the included journals. The initial search across 14 journals identified 77 articles. Restricting to journals with five or more relevant articles left 57 articles across five journals. After further exclusions, 31 articles across five journals were included in the review (Table 3).

\section{Pilot trial categories}

After data extraction, it was apparent that the pilot trials in the review could be classified into three categories: trials that were carried out in preparation for a future definitive trial (FDT); trials that evaluated the feasibility of a novel intervention but did not explicitly address a future definitive trial in their objectives (FNI); and trials that had no objectives, pre-defined assessments or 


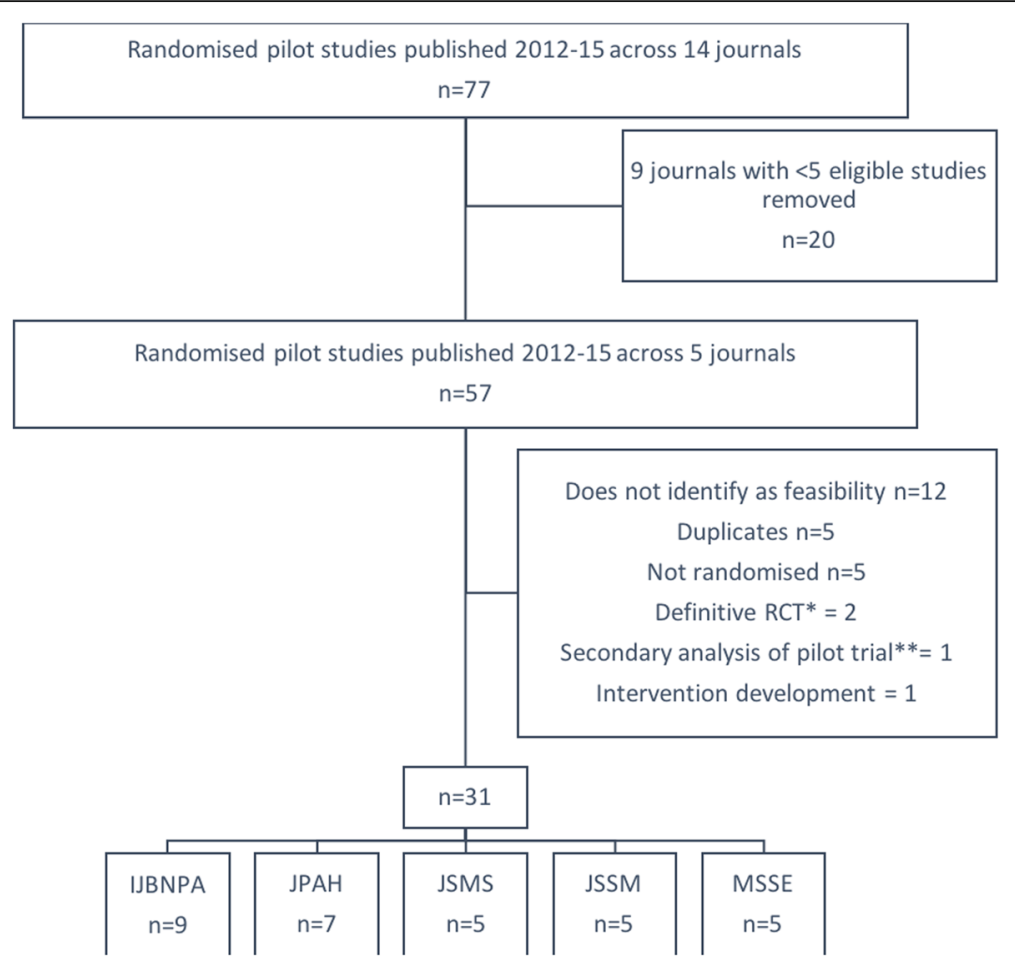

Fig. 1 Flow of articles into review. *With outcomes looking at the feasibility of translation to practice. ${ }^{* *}$ Exploring mediators of intervention effect. IJBNPA = International Journal of Behavioral Nutrition and Physical Activity; JPAH = Journal of Physical Activity and Health; JSMS = Journal of Science and Medicine in Sport; JSSM = Journal of Sports Science and Medicine; MSSE = Medicine \& Science in Sport \& Exercise

measurements to assess feasibility, referred to as non-feasibility (NF). Articles reporting FDT and FNI trials were assessed according to their adherence to all items listed in Table 2. As the NF trials did not address objectives relating to feasibility, these articles were excluded from the sections of the review that focus on the aspects of feasibility addressed and the discussion points that focus on the feasibility of a future definitive trial. The category assigned to each article is given in Table 3. All results are stratified by these three categories (FDT, FNI or NF).

Of the 31 trials included in the review, seven (23\%) were FDT, seven (23\%) were FNI and 17 (55\%) were NF. An interesting observation taken from Table 3 was that all seven of the FDT articles were published in IJBNPA. The FNI and NF articles both had a fairly even distribution across the five journals. In terms of the numbers of participants randomised in each trial, the FDT trials were substantially larger than the FNI and FN trials, with a median of 108 (IQR 130) participants. The FNI trials had a median of 48 (IQR 32) participants, and NF trials were the smallest, with a median of 19 (IQR 24).

\section{Literature review}

The full results for the literature review are detailed in Table 4. All data extracted in this review can be found in Additional file 1.

\section{Words in title}

Notable differences were found across the three categories of trials in terms of how they identified in the title of the article. FDT and FNI trials varied as to whether they identified as pilot or feasibility, all of them identifying as either or both. In contrast, $12(71 \%)$ of the NF trials identified as pilot in the title, and none as feasibility. In addition, only one (6\%) of the NF trials identified as randomised, compared with five (71\%) and three $(43 \%)$ of the FDT and FNI studies respectively. The original CONSORT 2010 statement advises that RCTs should identify as randomised in the title [6], thus highlighting the poor reporting in these trials in general as these were the guidelines they should have been following at the time of publication.

\section{Introduction}

Across all articles, the introduction focused on the scientific background and rationale for carrying out a definitive trial. However, none of the articles reported uncertainties in the context of relevant evidence in their introduction, and none gave a clear rationale for the need to carry out a pilot trial as opposed to a definitive trial. Even in the trials with feasibility objectives (FDT and FNI), the rationale for exploring feasibility was not supported with relevant evidence. 
Table 3 Articles included in literature review

\begin{tabular}{|c|c|c|c|c|}
\hline Author & Year & Journal & Title & $\begin{array}{l}\text { Participants } \\
\text { randomised } \\
(n)\end{array}$ \\
\hline $\begin{array}{l}\text { Anderson } \\
\text { et al. [14] }\end{array}$ & 2014 & IJBNPA & $\begin{array}{l}\text { Breast cancer risk } \\
\text { reduction-is it } \\
\text { feasible to initiate a } \\
\text { randomised controlled } \\
\text { trial of a lifestyle } \\
\text { intervention } \\
\text { programme (ActWell) } \\
\text { within a national } \\
\text { breast screening } \\
\text { programme? }\end{array}$ & 80 \\
\hline $\begin{array}{l}\text { Barnes et } \\
\text { al. [22] }\end{array}$ & 2015 & JPAH & $\begin{array}{l}\text { Feasibility and } \\
\text { preliminary efficacy of } \\
\text { the AMDE4Life } \\
\text { program: a pilot } \\
\text { randomised controlled } \\
\text { trial }\end{array}$ & 48 \\
\hline $\begin{array}{l}\text { Baruth et } \\
\text { al. [24] }\end{array}$ & 2015 & JPAH & $\begin{array}{l}\text { Effects of home-based } \\
\text { walking on quality of } \\
\text { life and fatigue out- } \\
\text { comes in early stage } \\
\text { breast cancer survivors: } \\
\text { a 12-week pilot study }\end{array}$ & 32 \\
\hline $\begin{array}{l}\text { Chau et al. } \\
\text { [36] }\end{array}$ & 2014 & IJBNPA & $\begin{array}{l}\text { The effectiveness of } \\
\text { sit-stand workstations } \\
\text { for changing office } \\
\text { workers' sitting time: } \\
\text { results from the } \\
\text { Stand@Work rando- } \\
\text { mised controlled trial } \\
\text { pilot }\end{array}$ & 42 \\
\hline $\begin{array}{l}\text { Ciolac et } \\
\text { al. [18] }\end{array}$ & 2015 & MSSE & $\begin{array}{l}\text { Prescribing and } \\
\text { regulating exercise } \\
\text { with RPE after heart } \\
\text { transplant: a pilot } \\
\text { study }\end{array}$ & 15 \\
\hline $\begin{array}{l}\text { Currie et } \\
\text { al. [37] }\end{array}$ & 2015 & JSMS & $\begin{array}{l}\text { Effects of resistance } \\
\text { training combined } \\
\text { with moderate- } \\
\text { intensity endurance or } \\
\text { low-volume high- } \\
\text { intensity interval exer- } \\
\text { cise on cardiovascular } \\
\text { risk factors in patients } \\
\text { with coronary artery } \\
\text { disease }\end{array}$ & 19 \\
\hline $\begin{array}{l}\text { Filingeri et } \\
\text { al. [20] }\end{array}$ & 2012 & JSSM & $\begin{array}{l}\text { The effects of vibration } \\
\text { during maximal } \\
\text { graded cycling } \\
\text { exercise: a pilot study }\end{array}$ & 12 \\
\hline $\begin{array}{l}\text { Gatterer et } \\
\text { al. [16] }\end{array}$ & 2014 & JSSM & $\begin{array}{l}\text { Shuttle-run sprint } \\
\text { training in hypoxia for } \\
\text { youth elite soccer } \\
\text { players: a pilot study }\end{array}$ & 16 \\
\hline $\begin{array}{l}\text { Gavin et al. } \\
\text { [19] }\end{array}$ & 2014 & JSMS & $\begin{array}{l}\text { Reproducibility of } \\
\text { lactate markers during } \\
4 \text { and } 8 \text { min stage } \\
\text { incremental running: a } \\
\text { pilot study }\end{array}$ & 19 \\
\hline $\begin{array}{l}\text { Gennuso } \\
\text { et al. [25] }\end{array}$ & 2013 & JPAH & $\begin{array}{l}\text { Resistance training } \\
\text { congruent with } \\
\text { minimal guidelines }\end{array}$ & 25 \\
\hline
\end{tabular}

Table 3 Articles included in literature review (Continued)

Author Year Journal Title Participants Type

randomised

(n)

\begin{tabular}{|c|c|c|c|c|}
\hline & & $\begin{array}{l}\text { improves function in } \\
\text { older adults: a pilot } \\
\text { study }\end{array}$ & & \\
\hline $\begin{array}{l}\text { Gorgey et } \\
\text { al. [38] }\end{array}$ & 2012 MSSE & $\begin{array}{l}\text { Effects of resistance } \\
\text { training on adiposity } \\
\text { and metabolism after } \\
\text { spinal cord injury }\end{array}$ & 9 & NF \\
\hline
\end{tabular}

[26]

for overweight and

obese men delivered

through professional

football clubs: a pilot

randomised trial

Greaves et 2015 IJBNPA Waste the waist: a

al. [30] pilot randomised

controlled trial of a

primary care based

intervention to

support lifestyle

change in people with

high cardiovascular

risk

Headley et 2012 MSSE Exercise training $21 \quad$ NF

al. [39]

improves HR

responses and

VO2peak in predialysis

kidney patients

Hutchison 2015 JSMS The effect of footwear

et al. [40] and foot orthoses on

transverse plane knee

motion during

running - a pilot study

Jago 2013 IJBNPA Feasibility trial $\quad 75$

et al. [27] evaluation of a

physical activity and

screen-viewing course

for parents of 6 to 8 -

year-old children:

teamplay

Jago et al. 2014 IJBNPA Randomised feasibility

539

FDT

[41]

trial of a teaching

assistant led

extracurricular physical

activity intervention

for 9- to 11-year olds:

action 3:30

2012 JJBNPA Bristol girls dance

et al. [42] project feasibility trial:

outcome and process

evaluation results

Kass 2013 JSSM A pilot study on the

et al. [43] effects of magnesium

supplementation with high and low habitual dietary magnesium intake on resting and recovery from aerobic and resistance exercise and systolic blood pressure 
Table 3 Articles included in literature review (Continued)

\begin{tabular}{ll}
\hline Author Year Journal Title & $\begin{array}{l}\text { Participants Type } \\
\text { randomised } \\
(n)\end{array}$
\end{tabular}

Kong et al.

[17]

Mark et al. 2013 JPAH
$[28]$

Martens et 2012 JPAH al. [44]

Martin et 2013 JSMS
al. [23]

Riley et al. 2015 JSMS [29]

Rogers et 2014 MSSE
al. [45]

Steeves et 2012 IJBNPA al. [46]

Suh et al. 2015 JPAH [21]

Thogersen- 2014 JPAH

Ntoumani

et al. [15]

Voglar et 2014 JSSM

al. [47]

A pilot walking

program promotes

moderate-intensity

physical activity during

pregnancy

effectiveness of

exercise videogame

bikes among families

in the home-setting: a

pilot study

The short-term efficacy 70

of a brief motivational

intervention designed

to increase physical

activity among college

students

Improving muscular

endurance with the

Mve fitness chair in

breast cancer survivors:

a feasibility and

efficacy study

Outcomes and process 54

evaluation of a

programming

integrating physical

activity into the

primary school

mathematics

curriculum: the EASY

Minds pilot

randomised controlled

trial

Biobehavioural factors 46

mediate exercise

effects on fatigue in

breast cancer survivors

FNI

NF intervention delivered
by non-supervised

technology in persons

with multiple sclerosis

Step by step: the

feasibility of a 16-week workplace lunchtime walking intervention for physically inactive employees

Kinesio taping in

young health subjects does not affect
Testing the

Yardley et 2014 IJBNPA
al. [49]

Table 3 Articles included in literature review (Continued)

Author Year Journal Title Participants Type

randomised

(n)

$\begin{array}{ll} & \text { postural reflex } \\ \text { reactions and } \\ \text { anticipatory postural } \\ \text { adjustments of the } \\ \text { trunk: a pilot study }\end{array}$

Volaklis et 2015 JSSM Acute pro- and

anti-inflammatory

responses to resistance

exercise in patients

with coronary artery

disease: a pilot study

Randomised

controlled feasibility

trial of a web-based

weight management

intervention with

nurse support for

obese patients in

primary care

IJBNPA International Journal of Behavioural Nutrition and Physical Activity;

JPAH Journal of Physical Activity and Health; MSSE Medicine \& Science in Sport \& Exercise; JSMS Journal of Science and Medicine in Sport; JSSM Journal of Sports Science and Medicine; FDT future definitive trial; FNI feasibility of novel intervention; $N F$ non-feasibility

Specific aspects of feasibility to be addressed were outlined in the introduction in all but one of the FDT articles. This article [14] simply stated "This study aims to assess the feasibility..." with no detail on the specific aspects of feasibility to be addressed. However, the specific aspects of feasibility to be addressed were detailed by Anderson et al., in the methods section of the article [14].

In contrast, only one (14\%) FNI article detailed specific aspects of feasibility to be addressed in their introduction [15]. However, five (71\%) of the FNI articles did detail aspects of feasibility to be addressed in the methods section. Of the remaining two, one revealed the specific aspect of feasibility that they were addressing in the discussion [16], while one did not address any specific aspects of feasibility, listing only outcomes to address the effectiveness of the intervention [17].

Inherent to the labelling of the NF trials, none of the NF articles detailed feasibility objectives in the introduction or in the methods section.

\section{5}

(1)

\section{Objectives}

None of the NF articles made reference to feasibility when stating their objectives. Thirteen (76\%) listed effectiveness of an intervention as their primary or sole objective, and the remaining four listed objectives relating to usefulness of a scale [18], reproducibility of a test [19], monitoring physiological mechanisms [20] and efficacy [21]. None of these articles outlined rationale for 
Table 4 Results from data extraction stratified by category of pilot trial (results given as number (\%) unless otherwise specified)

\begin{tabular}{|c|c|c|c|c|c|}
\hline Item & Description & $\begin{array}{l}\text { Feasibility of future } \\
\text { definitive trial }(n=7)\end{array}$ & $\begin{array}{l}\text { Feasibility of novel } \\
\text { intervention }(n=7)\end{array}$ & $\begin{array}{l}\text { Non-feasibility } \\
(n=17)\end{array}$ & $\begin{array}{l}\text { Total }(n \\
=31)\end{array}$ \\
\hline \multirow[t]{4}{*}{$1 a$} & Words in title & & & & \\
\hline & Pilot & $2(28)$ & $5(71)$ & $12(71)$ & $19(61)$ \\
\hline & Feasibility & $5(71)$ & $3(43)$ & $0(0)$ & $8(26)$ \\
\hline & Randomised & $5(71)$ & $3(43)$ & $1(6)$ & $9(29)$ \\
\hline \multirow[t]{3}{*}{$2 a$} & Introduction & & & & \\
\hline & Rationale for future definitive trial & $7(100)$ & $7(100)$ & $17(100)$ & $31(100)$ \\
\hline & Rationale for pilot trial & $0(0)$ & $0(0)$ & $0(0)$ & $0(0)$ \\
\hline \multirow[t]{2}{*}{$2 b$} & Objectives & & & & \\
\hline & $\begin{array}{l}\text { Objectives to assess the feasibility of a future } \\
\text { definitive trial }\end{array}$ & $7(100)$ & $0(0)$ & $0(0)$ & $7(23)$ \\
\hline \multirow[t]{6}{*}{$3 a$} & Design & & & & \\
\hline & Parallel & $4(57)$ & $5(71)$ & $8(47)$ & $17(55)$ \\
\hline & Crossover & $0(0)$ & $0(0)$ & $6(35)$ & $6(19)$ \\
\hline & Cluster & $2(29)$ & $0(0)$ & $0(0)$ & $2(6)$ \\
\hline & Waitlist control & $1(14)$ & $1(14)$ & $1(6)$ & $3(10)$ \\
\hline & Other & $0(0)$ & $1(14)$ & $2(12)$ & $3(10)$ \\
\hline \multirow[t]{3}{*}{5} & Treatment groups & & & & \\
\hline & Median number of treatment groups (IQR) & $2(0)$ & $2(0)$ & $2(0)$ & $2(0)$ \\
\hline & Control group & $7(100)$ & $5(71)$ & $11(65)$ & $23(74)$ \\
\hline \multirow[t]{8}{*}{$6 a$} & Aspects of feasibility addressed & & & & \\
\hline & Process (e.g. recruitment and retention rates) & $7(100)$ & $4(57)$ & - & $11(35)^{*}$ \\
\hline & Resources (e.g. cost, time, equipment) & $4(57)$ & $0(0)$ & - & $4(13)^{*}$ \\
\hline & Management (e.g. data entry and storage) & $0(0)$ & $0(0)$ & - & $0(0)^{*}$ \\
\hline & Scientific (e.g. dose) & $7(100)$ & $6(86)$ & - & $13(42)^{*}$ \\
\hline & $\begin{array}{l}\text { Sample size (inform sample size in future definitive } \\
\text { trial) }\end{array}$ & $4(57)$ & $0(0)$ & - & $4(13)^{*}$ \\
\hline & $\begin{array}{l}\text { Feedback (qualitative or quantitative feedback } \\
\text { from participants and staff) }\end{array}$ & $7(100)$ & $5(71)$ & - & $12(39)^{*}$ \\
\hline & $\begin{array}{l}\text { Median number of aspects addressed by each trial } \\
\text { (IQR) }\end{array}$ & $4(1)$ & $2(2)$ & - & $3(2)^{*}$ \\
\hline $6 c$ & Criteria for progression to future definitive trial & $0(0)$ & $0(0)$ & - & $0(0)^{*}$ \\
\hline \multirow[t]{3}{*}{$7 a$} & Participant numbers & & & & \\
\hline & Sample size calculation & $1(14)$ & $0(0)$ & $3(18)$ & $4(13)$ \\
\hline & Rationale for sample size & $4(57)$ & $1(14)$ & - & $5(36)^{*}$ \\
\hline \multirow[t]{2}{*}{$12 \mathrm{a}$} & Analysis & & & & \\
\hline & Hypothesis testing & $3(43)$ & $7(100)$ & $16(94)$ & $26(84)$ \\
\hline \multirow{4}{*}{$\begin{array}{l}20 \text { and } \\
21\end{array}$} & Discussion & & & & \\
\hline & Sources of potential bias & $2(29)$ & $2(29)$ & $4(24)$ & $8(26)$ \\
\hline & Remaining uncertainty about feasibility & $5(71)$ & $1(14)$ & - & $6(43)^{*}$ \\
\hline & Generalisability to future definitive trial & $3(43)$ & $0(0)$ & - & $3(21)^{*}$ \\
\hline \multirow[t]{4}{*}{$22 a$} & Implications for future definitive trial & $7(100)$ & $3(43)$ & - & $10(71)^{*}$ \\
\hline & Progression planned & & & & \\
\hline & Definitive RCT planned without any changes & $0(0)$ & $0(0)$ & - & $0(0)^{*}$ \\
\hline & Definitive RCT planned with changes from the & $6(86)$ & $1(14)$ & - & $7(50)^{*}$ \\
\hline
\end{tabular}


Table 4 Results from data extraction stratified by category of pilot trial (results given as number (\%) unless otherwise specified) (Continued)

\begin{tabular}{|c|c|c|c|c|c|}
\hline Item & Description & $\begin{array}{l}\text { Feasibility of future } \\
\text { definitive trial }(n=7)\end{array}$ & $\begin{array}{l}\text { Feasibility of novel } \\
\text { intervention }(n=7)\end{array}$ & $\begin{array}{l}\text { Non-feasibility } \\
(n=17)\end{array}$ & $\begin{array}{l}\text { Total }(n \\
=31)\end{array}$ \\
\hline & $\begin{array}{l}\text { Definitive RCT not planned because of major } \\
\text { problems with feasibility }\end{array}$ & $1(14)$ & $0(0)$ & - & $1(7)^{*}$ \\
\hline & Unclear & $0(0)$ & $6(86)$ & - & $6(43)^{*}$ \\
\hline & \multicolumn{5}{|l|}{ Progression realised } \\
\hline & Definitive trial completed & $3(43)$ & $0(0)$ & - & $3(21)^{*}$ \\
\hline & Definitive trial registered & $1(14)$ & $1(14)$ & - & $1(7)^{*}$ \\
\hline & Definitive trial not registered & $0(0)$ & $2(29)$ & - & $2(14)^{*}$ \\
\hline & No information & $3(43)$ & $4(57)$ & - & $8(57)^{*}$ \\
\hline
\end{tabular}

*Percentage of the 14 FDT and FNI trials

the need to carry out a pilot trial as opposed to a definitive trial.

\section{Design}

Of all 31 studies, a parallel design was used in 55\%, crossover in $19 \%$, cluster in $6 \%$, waitlist control in $10 \%$ and the remaining $10 \%$ had other designs. All six crossover trials were in the NF category, accounting for 35\% of the total NF trials.

\section{Treatment groups}

All but three of the trials were two-arm; of the three that were not, one was three- and two were four-arm. All of the FDT trials had a control arm, while a control arm was included in five $(71 \%)$ and $11(65 \%)$ of the FNI and NF studies respectively.

\section{Aspects of feasibility addressed}

The NF articles are omitted as they did not address feasibility. Process, scientific and feedback aspects were addressed by all seven of the FDT trials, and by four (57\%), six (86\%) and five (71\%) of the FNI trials respectively. Resources and sample size were both addressed by four (57\%) of the FDT, but by none of the FNI trials. Neither the FDT nor FNI trials addressed management as an aspect of feasibility. The median number of aspects of feasibility addressed was four (IQR one) in the FDT trials, compared with two (IQR one) in the FNI trials.

None of the trials detailed pre-specified criteria used to judge whether, or how, to proceed with a future definitive trial. However, two of the FNI trials specified a minimum attendance rate for the intervention to be deemed feasible $[22,23]$, but direct implications for a future randomised trial were not detailed.

\section{Participant numbers}

Rationale for the number of participants in the study was given in four (57\%) of the FDT articles and one (14\%) of the FNI articles. Of all 31 trials, four (13\%) carried out a sample size calculation using the primary outcome intended to test the effectiveness/efficacy of the intervention.

\section{Analysis}

Hypothesis testing was used in 26 (84\%) of the trials in total, despite only four (13\%) carrying out sample size calculations to ensure they were powered to do so. The practice of incorporating hypothesis testing into analysis was least prevalent in the FDT trials, but still almost half of these trials did so.

\section{Discussion}

Only eight (26\%) of the total articles addressed sources of potential bias in their discussion [17, 19, 24-29]. Bias should always be addressed when discussing the findings of a trial, regardless of the design, thus highlighting poor reporting of the discussion in general across the articles included in this review. As the remaining three discussion points (corresponding to items 20, 21 and $22 a$ listed in Table 2) refer to the feasibility of a future definitive trial, results are not reported for the NF studies. There was a clear discrepancy between the FDT and FNI articles in the reporting of these discussion points. Remaining uncertainty regarding feasibility and the implications of the pilot trial findings for a future definitive trial were well reported by most FDT articles. However, only three (43\%) of the FDT articles reported whether their methods and findings were generalisable to a future definitive trial.

As stated at the beginning of this section, the FNI articles did not explicitly address the feasibility of a future definitive trial in their objectives, instead considering the feasibility of a novel intervention. Only one of the FNI articles addressed the remaining uncertainty about feasibility [15], none considered the generalisability of their methods and findings to a future definitive trial and three $(43 \%)$ considered the implications of their findings to a future definitive trial. While this highlighted poor 
reporting of the discussion, it does demonstrate that some of the articles which did not explicitly consider the feasibility of a future definitive trial in their objectives then went on to address it in their discussion.

\section{Progression planned/realised}

In terms of progression to a future definitive RCT, there was a clear distinction in the quality of reporting between the FDT and FNI trials. All but one of the FDT trials planned to carry out a definitive RCT with changes based on the findings from the pilot trial, while plans for progression were unclear in the remaining one FDT trial. Conversely, plans for progression were unclear in all but one of the FNI trials, with the remaining one stating that a future definitive RCT was planned with changes based on pilot trial findings. None of the studies planned to progress to a future definitive trial without changes. Of the six studies in which the plans were unclear, the lack of clarity generally related to whether the suggested changes were due to be implemented in a future definitive RCT, or whether they should be tested in further feasibility work, prior to carrying out a definitive RCT.

Three $(43 \%)$ of the FDT trials progressed to definitive trials which have since been completed. One trial was registered [30]. However, following contact with Greaves (the lead author), we understand that the definitive trial does not directly correspond to the pilot trial, as it was carried out in a different region, under a different institution and with additional components, but uses the intervention piloted by Greaves et al. The protocol for the definitive trial has been published [31]. We did not obtain information from the remaining three FDT trials. Of the FNI trials, one had been registered as a definitive trial, two were not registered (although the authors stated intentions to do so when contacted) and we did not obtain any information on the remaining four FNI trials.

\section{Review of editorial policy}

Of the five journals, only the International Journal of Behavioral Nutrition and Physical Activity (IJBNPA) and Journal of Physical Activity and Health (JPAH) detailed their editorial policy for pilot trials on the journal website or in the author guidelines, both stating that they rarely accept pilot trials. Editors from all five journals responded to our enquiry regarding their editorial policy for pilot trials. Across all five journals, the editors stated that they generally do not accept pilot trials, although none stated that they would be automatically rejected without review, thus giving themselves some flexibility. Editors from IJBNPA and JPAH stated that they would only consider pilot studies that were novel and well-reported, while editors from the Journal of Science and Medicine in Sport (JSMS) and the Journal of Sports Science and Medicine (JSSM) did not state any criteria specific to pilot trials and requested only consistency with their author guidelines for research articles.

\section{Discussion}

In agreement with the findings of Shanyinde et al. [4], yet in contrast to those of Arain et al. [2], we found more articles identified as pilot than feasibility in this subject area. As the term feasibility was used only in articles with appropriate feasibility objectives (labelled FDT or FNI in this review), we did not observe the misuse of this term in our review. Conversely, the term pilot was used across articles that did not have feasibility objectives but instead tested an intervention's effectiveness on a small sample and at a single site (labelled NF in this review).

Our review found that, beyond the lack of clear feasibility objectives, the defining characteristics of the trials inappropriately labelled as pilot (NF trials) were that they had small sample sizes unsupported by sample size calculation and that they used hypothesis tests despite most being underpowered to do so. Not only is the inappropriate use of the term pilot misleading in this context, the conduct of such trials is in most cases unethical, as they put participants at risk for limited benefit [32]. These findings reinforce the need to disseminate the Conceptual Framework to Define Feasibility and Pilot Studies [5] to discourage inappropriate use of the term pilot and dissuade the practice of conducting a main trial in miniature to test effectiveness. Conditional on the dissemination of the Conceptual Framework to Define Feasibility and Pilot Studies [5], we anticipate very few, if any, such pilot trials will be identified in the follow-up review of articles published in 2018-21.

It is also of note that $35 \%$ of the inappropriately labelled pilot trials (NF trials) were cross-over in design. The benefit of this design is that, by making comparisons within rather than between participants, fewer participants are required to detect a change in the primary outcome compared with the number needed in an equivalent parallel trial [33]. However, this design has a history of inappropriate use, for example, in the field of fertility medicine [34].The motivation for choosing this design should be driven by context, not by low participant numbers. Only one of the six cross-over pilot trials in this review reported a sample size calculation, suggesting that the design could have been motivated by small sample size in the other five cases. The reason for conducting a pilot trial should be to inform a future definitive RCT. Therefore, the use of the cross-over design in pilot trials should be discouraged unless this is the intended design for the future RCT. To elaborate, feasibility issues in the pilot trial may be associated with the cross-over design and thus not applicable to the definitive trial of a different design. To our knowledge, the 
inappropriate use of the cross-over design in pilot trials has not been highlighted by previous reviews. However, it is likely to be of relevance across other areas of medical research and not only in physical activity.

Amongst the articles with feasibility objectives (FDT and FNI trials), many did not give appropriate reference to the future definitive trial in their introductions and discussions. However, we are hopeful that the publication of the CONSORT 2010 extension should ameliorate this issue, as the guidelines give explicit recommendations to both justify the need for a pilot in advance of a future definitive trial and to discuss the findings in relation to a future definitive trial. At the time of these articles' publication, no such guidelines existed.

A more concerning practice amongst the articles with feasibility objectives (FDT and FNI trials) was that many gave inappropriate emphasis to hypothesis tests of the primary outcome intended for the definitive trial. In a review published in 2004, Lancaster et al. recommend that the analysis of pilot studies "should be mainly descriptive" and that "results from hypothesis testing should be treated with caution, as no formal power calculations have been carried out" [3]. In the follow-up to this review, Arain et al. conclude that pilot studies still put "inappropriate emphasis on hypothesis testing" [2]. This raises the concern that these recommendations are either not reaching the relevant researchers or that they are being ignored. This calls for the need for both better scientific training and better dissemination of research methodology in the field of pilot and feasibility work.

The launch of the Pilot and Feasibility Studies journal in 2015 was a major step to address these issues and was described by Lancaster as providing "a forum for discussion of methodological issues that will lead to increased scientific rigour in this area" [12]. The journal also provides a platform for the publication of pilot and feasibility work. Our review of editorial policy, which identified an increasing reluctance to publish pilot work across the five reviewed physical activity journals, emphasises the need for a journal dedicated to the publication of pilot work.

While the multi-disciplinary nature of Pilot and Feasibility Studies has the benefit of sharing ideas across different subject areas, it is also crucial that subject-specific journals acknowledge the importance of pilot and feasibility work. This means considering prospective pilot trial submissions on the merit of their potential to inform future research, rather than the significance of an effect size. A key step to implementing these changes in editorial policy is the adoption of the CONSORT 2010 extension as a guideline for submissions identified as pilot or feasibility work.

To our knowledge, this is the first review to document the reporting and editorial policy of pilot trials in the field of physical activity. A strength of this work was the extensive use of the CONSORT 2010 statement as a framework for the data extraction form. The CONSORT 2010 statement was extended to pilot trials by a research team with expert input from the research community at multiple stages throughout the process. This is described in detail elsewhere [35]. A further strength of this work was the use of two reviewers for data extraction, which enhanced the accuracy and rigour of the review.

A weakness of this review was the small number of studies included with feasibility objectives. While this reflects the necessity of further work to encourage appropriate use of the term pilot, limited conclusions can be drawn from the trends observed within the 14 studies with feasibility objectives. We also anticipated that a greater number of physical activity journals would have published at least five pilot trials in 2012-15. This result either reflects the low number of pilot trials being published in physical activity journals generally or suggests that pilot trials of physical activity interventions are being published elsewhere. The 14 journals included in our search cover some of the highest impact physical activity journals, but the review of editorial policy (limited to the five journals included in the review) identified a reluctance to publish pilot trials in these journals. This could be indicative that physical activity researchers are publishing pilot trials in lower impact journals (not included in our review). An alternative explanation is that condition-specific journals are more open to publishing feasibility work (examples of condition-specific journals that relate to physical activity are Diabetes Care and the European Heart Journal). The second avenue of further work, outlined in the following paragraph, suggests an alternative approach to reviewing the literature which may provide clarity on this issue.

We suggest two avenues for further work. The first avenue is our intention to carry out a follow-up review using articles published in 2018-21. This follow-up review will use the same methods as the current review and will be used to evaluate the impact of the CONSORT 2010 extension in the field of physical activity. A second avenue for further work would be to identify a collection of articles reporting definitive trials in the field of physical activity and to look backwards to find whether appropriate feasibility work was carried out prior to the definitive trial, and if so, where the feasibility work was published, and how it influenced the design of the definitive trial. This approach would focus on the reporting and conduct of trials with feasibility objectives, thus addressing the weakness mentioned in the previous paragraph. Taken together, these two styles of review would give a more complete picture of the use of feasibility work undertaken for physical activity trials. We recommend that researchers in other fields carry out both styles of review in order to gain a thorough understanding of the feasibility work in their field. 


\section{Conclusions}

To summarise, the aim of this study was to review the reporting and methodological components of pilot trials published across a selection of physical activity journals, using the CONSORT 2010 extension as a guide. We designed the search criteria to identify external randomised pilot trials, as these are the trials specifically targeted by the CONSORT 2010 extension. We found that despite identifying as randomised pilot trials, over half (55\%) of the articles identified by our search criteria did not list objectives relating to the feasibility of conducting a future definitive trial. These findings are not unique to the field of physical activity and agree with the findings of three previous literature reviews, all reporting the frequent use of the terms pilot or feasibility to inappropriately describe trials with efficacy or effectiveness as their primary aim. In many cases, these trials had no objectives relating to feasibility [2-4].

\section{Additional file}

Additional file 1: Data extracted in literature review. (CSV 8 kb)

\section{Funding}

This study was supported by the NIHR Biomedical Research Centre at University Hospitals Bristol NHS Foundation Trust and the University of Bristol. The views expressed in this publication are those of the author(s) and not necessarily those of the NHS, the National Institute for Health Research or the Department of Health and Social Care. Elsie Horne is funded by an NIHR Doctoral Pre-Research Fellowship (RMFI-2015-06-03).

\section{Availability of data and materials}

The authors declare that the data supporting the findings of this study are available within the article and its Additional file 1.

\section{Authors' contributions}

$\mathrm{EH}$ and SL conceived the study. EH drafted the data extraction form and GL and $S L$ reviewed it. EH undertook the literature search and primarily reviewed all articles. RM was the second reviewer for all articles. EH drafted the manuscript and GL, RM, AC, AN and SL reviewed it. All authors read and approved the final manuscript.

\section{Ethics approval and consent to participate}

Not applicable.

\section{Consent for publication}

Not applicable.

\section{Competing interests}

The authors declare that they have no competing interests.

\section{Publisher's Note}

Springer Nature remains neutral with regard to jurisdictional claims in published maps and institutional affiliations.

\footnotetext{
Author details

${ }^{1}$ National Institute for Health Research Bristol Biomedical Research Centre University Hospitals Bristol NHS Foundation Trust and University of Bristol, 3rd Floor, Education \& Research Centre, Upper Maudlin Street, Bristol BS2 8AE, UK. ${ }^{2}$ Research Institute for Primary Care \& Health Sciences, Keele University, Staffordshire ST5 5BG, UK. ${ }^{3}$ Centre for Exercise, Nutrition and Health Sciences, School for Policy Studies, University of Bristol, 8 Priory Road, Bristol BS8 1TZ, UK.
}

Received: 8 May 2018 Accepted: 5 July 2018

Published online: 17 July 2018

\section{References}

1. Thabane L, Ma J, Chu R, Cheng J, Ismaila A, Rios LP, et al. A tutorial on pilot studies: the what, why and how. BMC Med Res Methodol. 2010;10:1.

2. Arain M, Campbell MJ, Cooper CL, Lancaster GA. What is a pilot or feasibility study? A review of current practice and editorial policy. BMC Med Res Methodol. 2010;10:67.

3. Lancaster GA, Dodd S, Williamson PR. Design and analysis of pilot studies: recommendations for good practice. J Eval Clin Pr. 2004;10:2.

4. Shanyinde M, Pickering RM, Weatherall M. Questions asked and answered in pilot and feasibility randomized controlled trials. BMC Med Res Methodol. 2011;11:117

5. Eldridge SM, Lancaster GA, Campbell MJ, Thabane L, Hopewell S, Coleman CL, et al. Defining feasibility and pilot studies in preparation for randomised controlled trials: development of a conceptual framework. PLoS One. 2016;11:3.

6. Eldridge SM, Chan CL, Campbell MJ, Bond CM, Hopewell S, Thabane L, et al. CONSORT 2010 statement: extension to randomised pilot and feasibility trials. BMJ. 2016:355:15239.

7. Wahid A, Manek N, Nichols M, Kelly P, Foster C, Webster P, et al. Quantifying the association between physical activity and cardiovascular disease and diabetes: a systematic review and meta-analysis. J Am Heart Assoc. 2016;5:9.

8. Kyu HH, Bachman VF, Alexander LT, Mumford JE, Afshin A, Estep K, et al. Physical activity and risk of breast cancer, colon cancer, diabetes, ischemic heart disease, and ischemic stroke events: systematic review and doseresponse meta-analysis for the Global Burden of Disease Study 2013. BMJ. 2016;354:13857.

9. Mutrie N, Foster C, Estabrooks P, Burton N, Baker G. Recruiting hard-to-reach populations to physical activity studies: evidence and experiences. J Phys Act. 2010;7:329-31.

10. Guy P, Joosen AMCP, Arnold KD, Goris AHC, Westerterp KR. Measuring freeliving energy expenditure and physical activity with triaxial accelerometry. Obes Res. 2012;13:8

11. Yates T, Griffin S, Bodicoat DH, Brierly G, Dallosso H, Davies MJ, et al. PRomotion Of Physical activity through structured Education with differing Levels of ongoing Support for people at high risk of type 2 diabetes (PROPELS): study protocol for a randomized controlled trial. Trials. 2015;16:289.

12. Lancaster GA. Pilot and feasibility studies come of age! Pilot Feasibility Stud. 2015;1:1.

13. Schulz KF, Altman DG, Moher D. CONSORT 2010 statement: updated guidelines for reporting parallel group randomised trials. BMJ. 2010;340:c332.

14. Anderson AS, Macleod M, Mutrie N, Sugden J, Dobson H, Treweek S, et al. Breast cancer risk reduction - is it feasible to initiate a randomised controlled trial of a lifestyle intervention programme (ActWell) within a national breast screening programme? Int J Behav Nutr Phys Act. 2014;11:156.

15. Thogersen-Ntoumani C, Loughren E, Duda J, Fox KR. Step by step: the feasibility of a 16-week workplace lunchtime walking intervention for physically inactive employees. J Phys Act Health. 2014;11:7.

16. Gatterer H, Philippe M, Menz V, Mosbach F, Faulhaber M, Burtscher M. Shuttle-run sprint training in hypoxia for youth elite soccer players: a pilot study. J Sport Sci Med. 2014;13:4.

17. Kong KL, Campbell CG, Foster RC, Peterson AD, Lanningham-Foster L. A pilot walking program promotes moderate-intensity physical activity during pregnancy. Med Sci Sport Exerc. 2014;46:3.

18. Ciolac EG, Castro RE, Greve JM, Bacal F, Bocchi EA, Guimaraes GV. Prescribing and regulating exercise with RPE after heart transplant: a pilot study. Med Sci Sport Exerc. 2015;47:7

19. Gavin JP, Willems ME, Myers SD. Reproducibility of lactate markers during 4 and 8 min stage incremental running: a pilot study. J Sci Med Sport. 2014;17:6.

20. Filingeri $D$, Jemni $M$, Bianco $A$, Zeinstra $E$, Jimenez $A$. The effects of vibration during maximal graded cycling exercise: a pilot study. J Sport Sci Med. 2012;11:3.

21. Suh Y, Motl RW, Olsen C, Joshi I. Pilot trial of a social cognitive theory-based physical activity intervention delivered by nonsupervised technology in persons with multiple sclerosis. J Phys Act Health. 2015;12:7.

22. Barnes AT, Plotnikoff RC, Collins CE, Morgan PJ. Feasibility and preliminary efficacy of the MADE4Life program: a pilot randomized controlled trial. J Phys Act Health. 2015:12:10.

23. Martin E, Battaglini C, Groff D, Naumann F. Improving muscular endurance with the MVe Fitness Chair in breast cancer survivors: a feasibility and efficacy study. J Sci Med Sport. 2013;16:4. 
24. Baruth M, Wilcox S, Der Ananian C, Heiney S. Effects of home-based walking on quality of life and fatigue outcomes in early stage breast cancer survivors: a 12-week pilot study. J Phys Act Health. 2015;12:1.

25. Gennuso KP, Zalewski K, Cashin SE, Strath SJ. Resistance training congruent with minimal guidelines improves function in older adults: a pilot study. J Phys Act Health. 2013;10:6.

26. Gray CM, Hunt K, Mutrie N, Anderson AS, Treweek S, Wyke S. Weight management for overweight and obese men delivered through professional football clubs: a pilot randomized trial. Int J Behav Nutr Phys Act. 2013;10:121

27. Jago R, Sebire SJ, Turner KM, Bentley GF, Goodred JK, Fox KR, et al. Feasibility trial evaluation of a physical activity and screen-viewing course for parents of 6 to 8 year-old children: teamplay. Int J Behav Nutr Phys Act. 2013;10:31.

28. Mark RS, Rhodes RE. Testing the effectiveness of exercise videogame bikes among families in the home-setting: a pilot study. J Phys Act Health. 2013;10:2.

29. Riley N, Lubans DR, Morgan PJ, Young M. Outcomes and process evaluation of a programme integrating physical activity into the primary school mathematics curriculum: the EASY Minds pilot randomised controlled trial. J Sci Med Sport. 2015;18:6

30. Greaves C, Gillison F, Stathi A, Bennett P, Reddy P, Dunbar J, et al. Waste the waist: a pilot randomised controlled trial of a primary care based intervention to support lifestyle change in people with high cardiovascular risk. Int J Behav Nutr Phys Act. 2015;12:1.

31. Pascale M, Murray N, Bachmann M, Barton G, Clark A, Howe A, et al. Study Protocol: the Norfolk Diabetes Prevention Study [NDPS]: a 46 month multicentre, randomised, controlled parallel group trial of a lifestyle intervention [with or without additional support from lay lifestyle mentors with type 2 diabetes] to preve. BMC Public Health. 2017;17:1

32. Halpern SD, Karlawish JHT, Berlin JA. The continuing unethical conduct of underpowered clinical trials. JAMA. 2002;288:3.

33. Sedgwick P. What is a crossover trial? BMJ. 2014;348:93191.

34. Elbourne DR, Altman DG, Higgins JPT, Curtin F, Worthington HV, Vail A. Meta-analyses involving cross-over trials: methodological issues. Int Epidemiol. 2002;31:1.

35. Thabane L, Hopewell S, Lancaster GA, Bond CM, Coleman CL, Campbell MJ, et al. Methods and processes for development of a CONSORT extension for reporting pilot randomized controlled trials. Pilot Feasibility Stud. 2016;2:1.

36. Chau JY, Daley M, Dunn S, Srinivasan A, Do A, Bauman AE, et al. The effectiveness of sit-stand workstations for changing office workers' sitting time: results from the Stand@Work randomized controlled trial pilot. Int J Behav Nutr Phys Act. 2014;11:127.

37. Currie KD, Bailey KJ, Jung ME, McKelvie RS, MacDonald MJ. Effects of resistance training combined with moderate-intensity endurance or lowvolume high-intensity interval exercise on cardiovascular risk factors in patients with coronary artery disease. J Sci Med Sport. 2015;18:6.

38. Gorgey AS, Mather KJ, Cupp HR, Gater DR. Effects of resistance training on adiposity and metabolism after spinal cord injury. Med Sci Sport Exerc. 2012;44:1.

39. Headley S, Germain M, Milch C, Pescatello L, Coughlin MA, Nindl BC, et al. Exercise training improves $\mathrm{HR}$ responses and $\mathrm{V}^{\prime} \mathrm{O} 2$ peak in predialysis kidney patients. Med Sci Sports Exerc. 2012;44:12

40. Hutchison L, Scharfbillig R, Uden H, Bishop C. The effect of footwear and foot orthoses on transverse plane knee motion during running - a pilot study. J Sci Med Sport. 2015;18:6.

41. Jago R, Sebire SJ, Davies B, Wood L, Edwards MJ, Banfield K, et al. Randomised feasibility trial of a teaching assistant led extracurricular physical activity intervention for 9 to 11 year olds: action 3:30. Int J Behav Nutr Phys Act. 2014;11:114

42. Jago R, Sebire SJ, Cooper AR, Haase AM, Powell J, Davis L, et al. Bristol girls dance project feasibility trial: outcome and process evaluation results. Int J Behav Nutr Phys Act. 2012;9:83

43. Kass LS, Skinner P, Poeira F. A pilot study on the effects of magnesium supplementation with high and low habitual dietary magnesium intake on resting and recovery from aerobic and resistance exercise and systolic blood pressure. J sport Sci Med 2013;12:1.

44. Martens MP, Buscemi J, Smith AE, Murphy JG. The short-term efficacy of a brief motivational intervention designed to increase physical activity among college students. J Phys Act Health. 2012;9:45.

45. Rogers LQ, Vicari S, Trammell R, Hopkins-Price P, Fogleman A, Spenner A, et al. Biobehavioral factors mediate exercise effects on fatigue in breast cancer survivors. Med Sci Sport Exerc. 2014;46:6.
46. Steeves JA, Bassett DR, Fitzhugh EC, Raynor HA, Thompson DL. Can sedentary behavior be made more active? A randomized pilot study of TV commercial stepping versus walking. Int J Behav Nutr Phys Act. 2012;9:95.

47. Voglar M, Sarabon N. Kinesio taping in young healthy subjects does not affect postural reflex reactions and anticipatory postural adjustments of the trunk: a pilot study. J Sport Sci Med. 2014;13:3

48. Volaklis KA, Smilios I, Spassis AT, Zois CE, Douda HT, Halle M, et al. Acute pro- and anti-inflammatory responses to resistance exercise in patients with coronary artery disease: a pilot study. J Sport Sci Med. 2015;14:1.

49. Yardley L, Ware LJ, Smith ER, Williams S, Bradbury KJ, Arden-Close EJ, et al. Randomised controlled feasibility trial of a web-based weight management intervention with nurse support for obese patients in primary care. Int J Behav Nutr Phys Act. 2014;11:67.

\section{Ready to submit your research? Choose BMC and benefit from:}

- fast, convenient online submission

- thorough peer review by experienced researchers in your field

- rapid publication on acceptance

- support for research data, including large and complex data types

- gold Open Access which fosters wider collaboration and increased citations

- maximum visibility for your research: over $100 \mathrm{M}$ website views per year

At BMC, research is always in progress.

Learn more biomedcentral.com/submissions 